\title{
Accommodative instability: relationship to progression of early onset myopia
}

Article

Accepted Version

Langaas, T. and Riddell, P. (2012) Accommodative instability: relationship to progression of early onset myopia. Clinical and Experimental Optometry, 95 (2). pp. 153-159. ISSN 1444-0938 doi: https://doi.org/10.1111/j.1444-0938.2011.00699.x Available at https://centaur.reading.ac.uk/27772/

It is advisable to refer to the publisher's version if you intend to cite from the work. See Guidance on citing.

To link to this article DOI: http://dx.doi.org/10.1111/j.1444-0938.2011.00699.x

Publisher: Wiley

All outputs in CentAUR are protected by Intellectual Property Rights law, including copyright law. Copyright and IPR is retained by the creators or other copyright holders. Terms and conditions for use of this material are defined in the End User Agreement.

\section{www.reading.ac.uk/centaur}

\section{CentAUR}

Central Archive at the University of Reading

Reading's research outputs online 


\section{Accommodative instability: relationship to progression of early onset myopia}

Article

Accepted Version

Langaas, T. and Riddell, P. M. (2012) Accommodative instability: relationship to progression of early onset myopia. Clinical and Experimental Optometry. ISSN 1444-0938 doi: 10.1111/j.1444-0938.2011.00699.x (In Press) Available at http://centaur.reading.ac.uk/26231/

It is advisable to refer to the publisher's version if you intend to cite from the work.

Published version at: http://dx.doi.org/10.1111/j.1444-0938.2011.00699.x

To link to this article DOI: http://dx.doi.org/10.1111/j.1444-0938.2011.00699.x

Publisher: Blackwell Publishing Asia

All outputs in CentAUR are protected by Intellectual Property Rights law, including copyright law. Copyright and IPR is retained by the creators or other copyright holders. Terms and conditions for use of this material are defined in the End User Agreement.

www.reading.ac.uk/centaur

\section{CentAUR}

Central Archive at the University of Reading 
Reading's research outputs online 


\section{Accommodative variability: predicting progression of early onset myopia}

Trine Langaas, PhD, Patricia M. Riddell, D.Phil,

Buskerud University College, Dep. of Optometry and Visual Science

Postbox 235, Frogs road 41, N-3603 Kongsberg, Norway (TL, PMR)

School of Psychology and Clinical Language Sciences, University of Reading

Earley Gate, Reading, RG6 6AL, UK (PMR)

Short running title: Predicting the progression of myopia

Corresponding Author: Dr Trine Langaas,

Buskerud University College, Department of Optometry and Visual Science,

Postbox 235, Frogs road 41, N-3603 Kongsberg, Norway

Phone: +47-32869664

Fax: $\quad+47-32869671$

E-mail: Trine.Langaas@hibu.no

Word count: 3819

Figures: 4

Tables: $\quad 1$

Date Submitted: $\quad$ April 262011 


\section{Abstract \\ Purpose}

In a previous study ${ }^{1}$ we demonstrated that children with early onset myopia had greater variability of accommodation than a group of emmetropic children. Since this study was correlational, we were unable to determine whether the greater variability caused or was caused by the myopia. To answer this question, we followed up the children 2 years later. We predicted that, if the greater accommodative variability was causing the myopia, variability at Visit 1 should predict the refractive error at Visit 2. Additionally, variability at Visit 1 should be related to change in refractive error between visits.

\section{Methods}

Twenty-one myopic and 18 emmetropic children were tested. Dynamic measures of accommodation were made using eccentric photorefraction (PowerRefractor) while children viewed targets set at three different accommodative demands.

\section{Results}

Both refractive error and accommodative variability at Visit 1 were highly correlated with the same measures at Visit 2. Children with myopia were found to have more variable accommodation at both Visit 1 and Visit 2. Variability in accommodation for the near target at Visit 1 was shown to predict myopic progression.

\section{Conclusions}

These results provide support for the hypothesis that greater accommodative fluctuations might provide a mechanism for myopic progression in early onset myopia.

Key words: myopia, accommodation, variability, prediction, children 


\section{Introduction}

The aetiology of early onset myopia is not yet clearly understood, despite the many studies that have suggested candidate mechanisms for this disorder ${ }^{2-11}$. For instance, evidence has suggested that development of myopia is associated with lag of accommodation $^{12-14}$. This could produce the myopia through hyperopic retinal defocus, particularly of the longer wavelengths of light ${ }^{15}$. In confirmation of this, both human and animal work has demonstrated that hyperopic retinal defocus is a sufficient stimulus to myopia ${ }^{3-5}$. However, more recent research has suggested that, while lag of accommodation is a common finding in patients with myopia, the lag of accommodation in early onset myopia is only present after the myopia has progressed, and therefore cannot be the causal mechanism ${ }^{16,17}$. Thus, other candidate mechanisms have been sought.

Another mechanism that has been investigated is whether a deficit in the ability to maintain a steady plane of accommodation, resulting in greater accommodative variability, in combination with hyperopic defocus resulting from accommodative lag, might drive myopia ${ }^{17-30}$. Several adult studies ${ }^{19-24}$ suggest that differences in accommodative variability are related to either the detection of errors in accommodation, or sensitivity to blur. Young, adult myopes show reduced sensitivity to blur in comparison to emmetropic children ${ }^{25}$, which might in turn be either a risk factor for development of myopia ${ }^{26}$ or a consequence of the myopia. Increase in variability of the accommodative response (either independently, or as a result of reduced sensitivity to blur), in combination with a lag of accommodation for near targets, will result in a blurred retinal image when integrated over time. This might result in failure to 
emmetropize by producing significant elongation of the eyeball ${ }^{6,7}$ providing a direct causal pathway. As a first step in disentangling possible relationships between accommodative variability and myopia, it is important to determine whether the increased variability precedes the myopia, and is related to myopic progression.

There is some debate in the literature over whether increased variability is only found in adults with late onset myopia ${ }^{26}$, or whether this can also be found in adults with early onset myopia ${ }^{31}$. For instance, Day et $\mathrm{al}^{26}$ measured accommodation to a high contrast Maltese cross and then calculated RMS values (accommodative variability) and used frequency analysis to calculate the relative size of microfluctuations in low, mid and high frequency components. They found that, whether measured as the power in individual frequency components (low frequency component only), or as the overall variability of the response collapsed across all frequencies, adults with late onset myopia were found to have greater accommodative variability than both emmetropic and early onset myopic adults. Differences in accommodative variability between adults with early versus late onset myopia are of potential interest since there are two possible interpretations of these findings. Differences in aetiology could result in these group differences, with greater accommodative variability providing a causal mechanism for late onset myopia. In this case, children who are developing myopia (early onset myopes) would not be expected to show increased variability.

Alternatively, differences in variability between these two adult myope groups could relate to the timing of accommodative variability with respect to the onset of myopia. If accommodative variability causes the myopia, it would have to be present before or during myopic progression (though not necessarily after progression). In this case, 
greater variability would be found in adults with late onset myopia but would not necessarily be found in those with early onset myopia. In comparison to this, children who are developing myopia (i.e. those who will become early onset adults) would be expected to show increased variability.

In a recent paper, we demonstrated that children with early onset myopia were found to have more variable accommodative focus than emmetropic children when tested concurrently with their myopic progression ${ }^{1}$. This previous research supported the theory that accommodative variability could be a potential mechanism for driving myopia. However, our previous study only demonstrated a correlation between accommodative variability and myopia, thus providing no evidence to determine the direction of causality. Increased variability of the accommodation response might be causal in the onset of myopia as a result of integration of a blurred retinal image over time, might be a consequence of insensitivity to blur which then drives the myopic progression, or myopia might result in increased variability in accommodation through insensitivity to blur.

In this paper, we report data from children who had been tested in our previous study and were invited back two years after their previous testing. Data from each visit was used to investigate possible causal relationships between accommodative variability and myopia. We predicted that variability in accommodation would correlate between the two visits if it related to the development of the myopia since myopia is continuing to progress in this age group. In addition, if greater accommodative variability drives myopia either directly or as a consequence of insensitivity to blur, we predicted that 
accommodative variability at the first visit (i.e. previous to the myopia) would predict both the myopia at the second visit, and myopic progression. The results of the study reported here suggest that greater variability of accommodation precedes and predicts myopic progression, though we are unable to determine whether variability is directly causal or is related to insensitivity to blur.

\section{Methods}

\section{Subjects}

For our previous study ${ }^{1}$, we invited participants who failed a local, optometric screening on the basis of myopia to participate. In addition, we recruited a group of emmetropic participants from local schools. In this study, we invited all participants that had produced useable data in our previous study to return to the lab for a two-year follow-up test, and 37 of these children returned for testing.

Approval was obtained from the National Committees for Research Ethics in Norway prior to the instigation of this study. The experiment followed the tenets of the Declaration of Helsinki. Experiments commenced after informed consent was obtained from parents/guardians and also from the participants if they were over the age of 12 years.

All participants had visual acuity of $6 / 6$ or better. Any participant with anisometropia or astigmatism greater than $1.0 \mathrm{D}$, with manifest strabismus or amblyopia or with a history of ocular health problems were excluded from the study. Participants were categorized twice: 1) on the basis of their refraction at Visit 1, and 2) on refraction at Visit 2. All 
participants in the myopic group had a subjective, non-cycloplegic refraction of at least $-0.5 \mathrm{D}$ mean spherical equivalent $(\mathrm{MSE}$, sphere $+(0.5 *$ cyl $)$ in each eye, and were considered to need a full time prescription for myopia by a qualified optometrist. The emmetropic group consisted of emmetropes and low hyperopes (subjective noncycloplegic refraction plano $\leq \mathrm{MSE}<+1.0 \mathrm{D})$ who were not considered to require optical correction.

Fifteen myopic participants from the original cohort agreed to be tested in the follow-up study. Since myopia was first identified at screening, there is no information available on the age of onset of myopia or its progression. However, since all participants were below the age of 15 at Visit 1, this was classified as early onset myopia ${ }^{2}$. Twenty-two emmetropic participants from the original cohort also returned for the follow-up study.

\section{Instruments}

Accommodation was recorded using an eccentric infrared photorefractor, the PlusOptix PowerRefractor II. It has been demonstrated to be a safe device for measuring accommodation respons $\mathrm{e}^{32}$, and a useful tool for measuring refraction in infants ${ }^{33}$. The PowerRefractor includes a dynamic mode of operation in which the refractive status of both eyes is recorded continuously at a sampling frequency of $12.5 \mathrm{~Hz}$. Pupil size was within the range of 3.5-7 mm, a range that has previously been reported to provide consistent accommodative responses ${ }^{32}$. A more detailed description of this procedure has been reported previously ${ }^{1}$. 


\section{Measurement procedure}

At each visit, all participants were corrected for distance and wore their best subjective refractive correction with full aperture lenses in a trial frame during the test procedure. The trial frame was fitted on the participant so that the line of refraction through the refractometer was not disrupted. Any refractive error in $0.25 \mathrm{D}$ steps (sphere and cylinder) evident during subjective examination was corrected, with the result that all myopes and most of the emmetropic participants wore refractive lenses during the procedures at Visit 1. At Visit 2, all participants viewed the targets through either plano or correcting lenses as appropriate. This ensured that variability in accommodation due to uncorrected refractive error was eliminated, and that testing conditions were equivalent between the two groups. In addition, since both groups were tested through lenses, any difference in variability between the groups cannot be the result of instrument error due to reflections from the trial frame or correction lens.

The subjects were seated in front of the PowerRefractor with the head stabilized on a head and chin rest. Fixation targets were identical to those used at Visit 1 (printed letters equivalent to letter size N5 and scaled for fixation distance: see Langaas et al, 2008 ${ }^{1}$; Figure 1).

The participants were instructed to look at the three targets in a set order: near (4D); middle (2D); far (0.25D); near (4D); far (0.25D) and middle (2D). This pseudorandom target order ensured that all participants viewed all distances twice with the same variable step changes across the trial. Accommodative response was recorded 
continuously during the procedure. Data was viewed on-line during collection to determine when the participant was accommodating steadily at each target and to ensure that data was being collected. The experimenter waited until a steady accommodative response was achieved for an estimated 2-3 secs on the real time output at each distance before asking the participant to move to the next target.

The data was stored off-line and transferred to spreadsheets for later data analysis. Accommodation was analysed for one eye only. Blinks were first eliminated from the data, as in our previous study ${ }^{1}$. Out of the initial pool of 37 participants that returned for follow-up testing, the data for eight participants (one myope and seven emmetropes) had to be discarded during off-line analysis since the data revealed that the participant had not achieved a steady accommodative response lasting more than one second at more than two target distances. This was usually the result of inattention, and/or blinks in the data, which reduced the duration of the accommodative response. In all 29 participants, 13 myopes and 16 emmetropes (at time of Visit 2) were included in the study.

\section{-----Table 1 about here----}

Table 1 shows the mean age, spherical equivalent non-cycloplegic refraction and time between visits for the myopes and emmetropes at each visit. There was no significant difference in age at either visit, or time between visits but, as by definition, the refractive error was significantly different between the two groups. 
For all participants, we chose sections of accommodative data from the best eye, right eye when possible, for each fixation target that lasted 2-3 seconds. The starting point of each fixation was chosen as the first point at which the accommodative response remained at a consistent new plane for at least 1 second and the end point was chosen as the point before which there was a change of at least $0.75 \mathrm{D}$ in accommodation towards the next target plane, as explained previously ${ }^{1}$. Although the number of points chosen at each distance and pupil size was not constant across participants, these measures were not considered here, since they were shown to have no effect on accommodative variability in our previous study ${ }^{1}$.

\section{Analysis}

Variability in the accommodative response was defined as the standard deviation of that response across time. Since each participant viewed two presentations of each target distance, mean differences were analysed using repeated measures ANOVAs with target presentation order and distance as within-subject factors and refractive error group as a between-subjects factor. We have reported F-values, $\mathrm{p}$ values and observed power for these analyses. Pairwise comparisons (Bonferroni corrected) were used for post-hoc comparisons. Bland Altman plots were used to examine relationships between measures across visits.

\section{Results}


A Bland Altman difference plot was used to investigate the repeatability of refractive error and accommodative variability across visits. Figure 1a shows the Bland Altman plot for the change in refractive error between Visits 1 and 2. There is no significant bias between measures at visits 1 and $2(\mathrm{t}=1.55$, n.s.). A regression analysis showed that there was a significant positive correlation between the bias and the mean refractive error $\left(r^{2}=0.26, p=0.005\right)$. This suggests that the children who were myopic at the first visit continued to show a myopic progression between visits. Finally, there was no consistent increase in the range of bias across refractive errors in this small sample. Figure $1 \mathrm{~b}$ shows the Bland Altman plots for the variability in accommodation for each target distance. The bias between measures was small at each target distance (largest bias was $-0.05 \mathrm{D}$ for the near target). The bias at the near target was significant $(\mathrm{t}=-$ $2.36, \mathrm{p}=0.025)$ demonstrating that variability at visit $2($ mean $=0.36)$ was greater than at time $1($ mean $=0.31)$. There was no significant bias for either the middle or far target (middle: $\mathrm{t}=0.026$, n.s.; far: $\mathrm{t}=-0.67$, n.s.). For the near target, a regression analysis showed that the bias became more negative with increasing variability $\left(r^{2}=0.31, p=\right.$ 0.002), suggesting that children who were more variable at the first visit increased their variability more at the second visit than more stable children. This trend approached significance for the middle target $\left(r^{2}=0.13, p=0.054\right)$ but was not found for the far target $\left(r^{2}=0.009\right.$, n.s. $)$.

\section{-----Figure 2 about here----}

We first investigated whether greater variability in accommodation at each visit was associated with myopic refractive status measured at that visit. Figure 2 shows the SD at 
each target distance by group for Visit 1 and 2. This demonstrates that the myopic group appears to show greater accommodative variability at each visit when compared to the emmetropic group. A repeated measures ANOVA was used to determine whether there were significant differences between myopes and emmetropes for each target distance at Visit 1. We analyzed one within subject factor: distance (three levels: Near, Middle and Far), and one between-subjects factor: group (two levels: myopic and emmetropes). At Visit 1, there was a main effect of refractive error $\left(F_{1,27}=8.37, p=0.007\right.$, Observed Power $=0.8$ ). The myopic group showed more accommodative variability than the emmetropic group. There was also a main effect of distance $\left(\mathrm{F}_{1,27}=42.78, \mathrm{p}<0.0001\right.$, Observed Power $=1$ ). Pairwise comparisons demonstrated that variability at near was greater than variability at the middle and far targets (all $p<0.0001$ ), but that there was no difference in variability between the middle and far targets. There were no significant interactions. A second repeated measures ANOVA was computed to compare differences in variability at each target distance for Visit 2. This demonstrated a marginally significant main effect of refractive error (Visit 2: $F_{1,27}=3.75, p=0.063$, Observed Power $=0.46)$. There was a significant main effect of distance $\left(F_{1,27}=31.34\right.$, $\mathrm{p}<0.0001$, Observed Power $=1)$. Again, pairwise comparisons demonstrated that that variability at near was greater than variability at the middle and far targets (all $p<$ 0.0001), but that there was no difference in variability between the middle and far targets. However, it should be noted that the estimate of power for variability at Visit 2 was lower than for Visit 1, suggesting that this result is less reliable. 
We were interested in whether the difference in variability between myopic and emmetropic participants at Visit 1 (predictive) or Visit 2 (concurrent) was more associated with refractive group at Visit 2 (Figure 3). Since variability was significantly greater for the near target than for middle or far targets at each visit, only the near target variability was used in this analysis since this maximises the power in the analysis. An ANOVA was run for variability at near for Visit 1 and Visit 2, with participants categorized by their refractive status at Visit 2 (myopic or emmetropic). There was a significant main effect of group for Visit $1\left(\mathrm{~F}_{1,27}=7.91, \mathrm{p}<0.009\right.$, Observed Power $=$ $.77)$ but not for Visit $2\left(\mathrm{~F}_{1,27}=1.11\right.$, n.s., Observed Power $\left.=.18\right)$. This demonstrates that the variability at Visit 1 is a better predictor of myopia at Visit 2 than the concurrent variability at Visit 2.

\section{-----Figure 4 about here----}

Finally, to determine whether variability at the first visit could be used to predict the degree of myopic progression, we regressed the variability at Visit 1 against progression in myopia (Figure 5). This showed a significant predictive effect of variability on myopic progression $\left(\mathrm{r}^{2}=0.15, \mathrm{p}=0.046\right)$. Thus, the greatest myopic progression was found for children who showed the greatest variability at the near target at Visit 1.

\section{Discussion}

In a previous study ${ }^{1}$ it was found that a group of children with early onset myopia demonstrated greater accommodative variability than a group of emmetropic children. It was postulated that this increase in accommodative variability could result in an 
increase in retinal blur and hence be a causal factor in the development of myopic refractive error. Alternatively, the increased accommodative variability might result from the myopia. A two-year follow-up study was therefore instigated to investigate whether the observed increase in accommodative variability would predict or be concurrent with myopic refractive error. All children who had provided measureable data at the first visit were invited back for retest two years after their first visit. Measures of accommodative variability were repeated at the two year follow up visit.

Bland Altman plots of the repeatability of refractive error showed that there was no significant bias in refractive error between visits, however a regression analysis demonstrated that the more myopic children changed their refraction more (i.e. became more myopic) than emmetropic children. The refractive errors changed by a mean of $0.75 \mathrm{D}$ (or $-0.325 \mathrm{D}$ per year) for the myopic group, and $-0.07 \mathrm{D}$ (or $-0.035 \mathrm{D}$ per year) for the emmetropic group. This compares favorably with previous studies that found that for early onset myopes, after the onset of myopia the progression is typically -0.39 to $-0.52 \mathrm{D}$ per year ${ }^{34}$.

Accommodative variability across visits showed a significant bias for the near target only with children becoming more variable at the second visit. Regression analysis showed that there was a relationship between mean variability and bias, with a greater bias in children who showed a greater variability. Thus, children who showed a large accommodative variability at the first visit demonstrated the greater increase in variability across visits. 
As in our previous study ${ }^{1}$, the accommodation variability was greater for the near target than the middle and distance targets in both groups. This could be the result of the larger accommodative responses required to overcome the accommodative demand of the near target in comparison to the middle and far targets.

In the previous study, concurrently measured accommodation variability was significantly greater for a group of early onset myopes compared to an age matched group of emmetropic children both for near (4 D) and far (0.25 D), but not for middle ( 2 D) targets. This finding was replicated in this follow-up study, where accommodative variability was found to be greater for the myopic group. In this study, we were also able to determine whether accommodative variability measured two years earlier at Visit 1 was related to refractive error at Visit 2. When participants were grouped according to their refractive status at Visit 2, the myopic group was found to have had significantly greater accommodative variability at Visit 1 than the emmetropic group. At Visit 2, when the participants were categorized by the refractive status at the concurrent second visit, the accommodation variability was not significantly different between groups.

A regression analysis looking at the relation between variability in accommodation for the near target at Visit 1 and myopic progression demonstrated that variability was predictive of myopic progression. Thus, while previous studies have failed to show a predictive relationship between overall lag of accommodation and myopic progression $^{17}$, this study suggests that the combination of lag of accommodation for 
near targets, and variability in accommodation might be used to predict myopia progression.

Previous studies have reported that accommodative variability is increased in adults with late-onset, but not early-onset myopia ${ }^{26}$.This difference could have arisen from differences in the aetiology of early-onset versus late-onset myopia. In this case, increased accommodative variability would not have been expected in our early onset myopes assessed while their myopia was progressing. The alternative hypothesis was that the accommodative variability is present during myopic progression, but later stabilizes. This latter hypothesis is supported by the findings reported here.

Reduced sensitivity to blur has been reported in adults with myopia ${ }^{25}$, and this has been proposed as a possible mechanism for the development of myopia ${ }^{6,7}$. According to this theory, if sensitivity to blur is reduced, accommodative accuracy is decreased, and thus larger errors of accommodation are tolerated. Thus, relatively large changes in accommodation might not produce sufficient changes in blur to be noticed and therefore would not be corrected, resulting in greater variability of accommodation. Integration of the increased blur resulting from greater errors of accommodation over time would then drive myopic progression.

\section{Conclusion}

The results of this study provide support for the hypothesis that greater variability in accommodation might drive myopic progression in children with early onset myopia but is unable to determine whether the greater accommodative variability drive the myopic 
progression directly or is a consequence of insensitivity to blur which then drives myopia.

\section{Acknowledgements}

Thanks to Ellen Svarverud, Katrine H. Larsen, Ann Ystenæs, Cecilie Bjørset, Irene Langeggen, Marit H. Fjerdingstad and Jorunn Lid for help with testing the children. Preliminary results were presented at Association for Research in Vision and Ophthalmology conference, Fort Lauderdale, Florida 2009.

This study was supported by grant no: 176541/V10 from The Norwegian Research Council.

\section{References}

1. Langaas T, Riddell PM, Svarverud E, Ystenǽs AE, Langeggen I, Bruenech JR. Variability of the accommodation response in early onset myopia. Optom Vis Sci 2008 ;85: 37-48.

2. Grosvenor TP, Goss DA. Clinical Management of Myopia. Boston: ButterworthHeinemann, 1999.

3. Flitcroft DI. A model of the contribution of oculomotor and optical factors to emmetropization and myopia. Vision Res 1998; 38: 2869-79.

4. Jiang BC, Morse SE. Oculomotor functions and late-onset myopia. Ophthal Physiol Opt $1999 ; 19: 165-72$.

5. Hung GK, Ciuffreda KJ. A unifying theory of refractive error development. Bull Math Biol 2000; 62 :1087-108. 
6. Nevin S, Schmid K, Wildsoet C. Sharp vision: A prerequisite for compensation to myopic defocus in the chick? Cur Eye Res 1998; 17: 322-31.

7. Norton T, Gamlin P. The near responce, emmetropia and myopia. Ophthal Physiol Opt 1999; 19: 79-80.

8. Pacella R, McLellan J, Grice K, del Bono E, Wiggs J, Gwiazda J. Role of genetic factors in the etiology of juvenile-onset myopia based on a longitudinal study of refractive error. Optom Vis Sci 1999; 76: 381-6.

9. Curtin BJ. The Myopias: Basic Science and Clinical Management. Philadelphia: Harper and Row; 1985;103-51.

10. Wallman J, Winawer J. Homeostasis of eye growth and the question of myopia. Neuron 2004; 43: 447-68.

11. Abbott M, Schmid K, Strang M. Differences in the accommodation stimulusresponse curve of adult myopes and emmetropes. Ophthal Physiol Opt 1998; 18: 1320.

12. Rosenfield M, Desai R, Portello JK. Do progressing myopes show a reduced accommodative response? Optom Vis Sci 2002; 79: 268-73.

13. Gwiazda J, Thorn F, Bauer J, Held R. Myopic participants show insufficient accommodative response to blur. Invest Ophthalmol Vis Sci 1993; 34: 690-4.

14. Gwiazda J. Thorn F, Held R. Accommodation, accommodative convergence, and response AC/A ratios before and at the onset of myopia in participants. Optom Vis Sci 2005; 82: 273-8.

15. Rucker FJ, Kruger PB. Cone contribution to signals for accommodation and the relationship to refractive error. Vision Res 2006; 46: 3079-89. 
16. Mutti D, Mitchell G, Hayes J, Jones L, Moescherger M, Cotter S, et al. Accommodative lag before and after the onset of myopia. Invest Ophthalmol Vis Sci 2006; 47: 837-46.

17. Weizhong L, Zhikuan Y, Wen L, Xiang, C, Jian, G. A longitudinal study on the relationship between myopia development and the accommodation lag in myopic children. Ophthal Phyisiol Opt 2008; 28: 57-61.

18. Candy TR, Bharadwaj SR. The stability of steady state accommodation in human infants. J Vision 2007; 7: 1-16.

19. Alpern M. Variability of accommodation during steady fixation at various levels of illuminance. J Opt Soc Am 1958; 48: 193-7.

20. Campbell FW, Robson JG, Westheimer G. Fluctuations of accommodation under steady viewing conditions. J Physiol (Lond.) 1959; 145: 579-94.

21. Denieul P. Effects of stimulus vergence on mean accommodation response, microfluctuations of accommodation and optical quality of the human eye. Vision Res 1982; 22: 561-9.

22. Kotulak JC, Schor C. A computational model of the error detector of human visual accommodation. Biol Cybern 1986; 54: 189-94.

23. Heron G, Schor C. The fluctuations of accommodation and ageing. Ophthal Physiol Opt 1995; 15: 445-9.

24. Miege C, Denieul P. Mean response and oscillations of accommodation for various stimulus vergences in relation to accommodation feedback emmetropic. Ophthal Physiol Opt 1988; 8: 165-71.

25. Rosenfield M, Abraham-Cohen JA. Blur sensitivity in myopes. Optom Vis Sci 1999; 76: 303-7. 
26. Day M, Strang NC, Seidel D, Gray LS, Mallen, E. A. H. Refractive group differences in accommodation microfluctuations with changing accommodation stimulus. Ophthal Physiol Opt 2006; 26: 88-96.

27. Seidel D, Gray L, Heron G. Retinotopic accommodation responses in myopia. Invest Ophthalmol Vis Sci 2003; 44: 1035-41.

28. Seidel D, Gray L, Heron G. The effect of monocular and binocular viewing on the accommodation response to real targets in emmetropia and myopia. Optom Vis Sci 2005; 82: 279-85.

29. Harb E, Thorn F, Troilo D. Characteristics of accommodative behavior during sustained reading in emmetropes and myopes. Vision Res 2006; 46: 2581-2592.

30. Stark LR, Atchison DA. Pupil size, mean accommodation response and fluctuations of accommodation. Ophthal Physiol Opt 1997; 17: 316-23.

31. Day M, Sidel D, Gray LS, Strang NC. The effect of modulating ocular depth of focus upon accommodation microfluctuations in myopic and emmetropic subjects. Vision Res 2009; 49: 211-8.

32. Choi M, Weiss S, Schaeffel F, Seidmann A, Howland HC, Wilhelm B. Laboratory, clinical and kindergarten test of a new eccentric infrared photorefractor (PowerRefractor). Optom Vis Sci 2000; 77: 537-48.

33. Blade PJ, Candy R. Validation of the PowerRefractor for measuring human infant refraction. Optom Vision Sci 2006; 83: 346-53.

34. Mutti, D.O., et al., Refractive Error, Axial Length, and Relative Peripheral Refractive Error before and after the Onset of Myopia. Invest. Ophthalmol. Vis. Sci., 2007; 48: 2510-9. 
Figure 1: Bland Altman plots illustrating the difference between measures taken at Visit 1 and Visit 2 (two years later). Figure 1 a shows the association between refractive error at Visit 1 and 2 . Figure $1 \mathrm{~b}$ shows the association between variability between refractive error at Visit 1 and 2 for each target distance.

Figure 2: Variability in accommodation at each target distance for the emmetropic (filled symbols, dotted lines) and myopic (open symbols, dashed line) groups. Figure 2a shows the variability at Visit 1 , and Figure $2 \mathrm{~b}$ shows the variability two years later at Visit 2. In both cases, the myopes show greater variability of accommodation than the emmetropes.

Figure 3: Variability in accommodation for the myopic and emmetropic groups when categorized by their refraction at Visit 2. There is a significant group difference in accommodative variability in accommodation at Visit 1 (before the myopic categorization), and at Visit 2 (concurrent with the myopic categorization).

Figure 4: Scatterplot showing the relationship between variability for near at Visit 1 and myopic progression. There was a significant correlation between these measures $\left(\mathrm{r}^{2}\right.$ $=0.15, \mathrm{p}=0.046$ ). 
Table 1: Subject Details

\begin{tabular}{lccccccccc}
\hline & \multicolumn{4}{c}{ Visit 1 } & \multicolumn{4}{c}{ Visit 2 } \\
& \multicolumn{2}{c}{ Control (15) } & \multicolumn{2}{c}{ Myopes (14) } & \multicolumn{2}{c}{ Control (16) } & Myopes (13) \\
& Mean & SE & Mean & SE & Mean & SE & Mean & SE \\
Age (years) & 13.85 & 0.10 & 13.78 & 0.65 & 16.04 & 0.11 & 16.00 & 0.68 \\
Refraction (D) & 0.10 & 0.07 & -1.37 & 0.24 & 0.11 & 0.09 & -2.27 & 0.28 \\
Between visits (years) & & & & & 2.27 & 0.03 & 2.15 & 0.04 \\
\hline
\end{tabular}

